Dataset Paper

\title{
Morphological Characterisation of Some Important Indian Garcinia Species
}

\author{
Utpala Parthasarathy and O. P. Nandakishore \\ Indian Institute of Spices Research, Calicut, Kerala 673012, India \\ Correspondence should be addressed to Utpala Parthasarathy; utpala_p@yahoo.com \\ Received 20 June 2013; Accepted 29 July 2013; Published 23 April 2014 \\ Academic Editors: P. J. Correia, D. Fangueiro, C. Machida, and S. Penna
}

Copyright (C) 2014 U. Parthasarathy and O. P. Nandakishore. This is an open access article distributed under the Creative Commons Attribution License, which permits unrestricted use, distribution, and reproduction in any medium, provided the original work is properly cited.

\begin{abstract}
The genus Garcinia has over 200 species distributed in the tropics of the world. About 35 species occur in India, many of which are endemic and economically important with immense medicinal properties. However, lack of awareness, coupled with habitat destruction, leads to genetic erosion of this forest resource and many species are threatened. The Indian Institute of Spices Research (IISR), Calicut, has Garcinia genetic resources' collection of 15 species of Western Ghats and Eastern Himalaya species. The morphological characterisation of the species of these two different eco systems indicates that there are variations within the species of the same ecosystem while there are similarities in the species of two different ecosystems.
\end{abstract}

\section{Introduction}

The genus Garcinia (Family: Clusiaceae) consists of over 200 species distributed in the tropics of the world chiefly in Asia, Africa, and Polynesia. They are evergreen polygamous trees, shrubs, and herbs. About 35 species are reported to exist in India, many of which are endemic and economically important with immense medicinal properties [1].

In India, species of Garcinia grow extensively in semiwild state, in the Konkan region of Maharashtra, Goa, coastal areas of Karnataka and Kerala, and evergreen forests of Assam, Khasi, Jantia hills, Nagaland, West Bengal, and Gujarat. In Malabar and Konkan regions of Southern India, they are used in garnishing curries and also as a replacement for tamarind. In North Eastern India, the sundried slices of the fruits are used for culinary purposes and as folk medicine. Some species like Garcinia cambogia, G. indica, and G. cowa are cultivated in certain parts of India. G. pedunculata, G. kydia, G. cowa, and G. lanceaefolia are the most important species in north eastern parts of India. Many species of Garcinia have fruit with edible arils and are eaten locally. The bestknown species is the mangosteen (G. mangostana), which is now cultivated throughout Southeast Asia and other tropical countries. The seeds of $G$. indica fruits yield valuable edible fat known as kokum butter. The fruits of Garcinia are a food source for several animals [2]. Most species in Garcinia are known for their gum resin which is used as purgative or cathartic. Fruits of some Garcinia species are also one of the richest sources of red pigments in the plant kingdom. Fruit and syrup of G. indica are very popular in Konkan region and are antioxidant and antibacterial [3].

Garcinia is the source for a natural diet ingredient (-) hydroxycitric acid. HCA (1,2dihydroxypropane-1,2,3tricarboxylic acid) which is an antiobesity compound is present in the fruit rind and leaves of Garcinia and is known to inhibit lipid and fatty acid synthesis in living systems [4]. HCA is also a hypocholesterolemic agent [5-7]. On a dry weight basis, HCA constitutes about $20-30 \%$ of the fruit. Lack of knowledge, coupled with habitat destruction, leads to genetic erosion of this forest resource and many species are threatened [8]. They need to be studied and conserved. In this study, we tried to characterize the morphological features of the species collected from Western Ghats and Himalayan Foot hills. Nine species studied here are the most common species of the two ecosystems, but the awareness about the crop or its medicinal value is very less. Most Garcinia species occur only as natural populations and are known only locally. Many Garcinia species have edible arils and are eaten locally. Some species fruits are highly esteemed in one region but are unknown just a few hundred kilometers away. Perhaps, 
trees are cut due to lack of awareness and popularization of importance of Garcinia will help in conserving the local populations of this genus. Here it is worth to mention that the climatic parameters of both ecosystems are almost the same specially the altitude and rainfall pattern. The altitude varies from 100 to 600 MLS, while the annual rainfall varies from 1500 to $4500 \mathrm{~mm}$.

\section{Methodology}

The morphological features of the Indian Garcinia were observed for mature and bearing trees.

A total of 9 species were studied here from two distinct geographical locations, namely, Western Ghats and Northeast Himalayan foothills.

Species selected for this study were G. indica, G. gummigutta, G. cowa, G. subelliptica and G. mangostana from Western Ghats; G. pedunculata, G. lanceaefolia, and G. kydia from NE Himalayas; and G. xanthochymus from both the ecosystems.

G. gummi-gutta is also known as G. cambogia and G. xanthochymus as G. tinctoria. Garcinia cowa and G. kydia are considered as synonymous though they show some variations in their morphological features [9].

The plant height was calculated by fixed angle of elevation method, in which the distance from the tree is measured, at which the top of the tree coincides with the tip of the right triangle making an angle of $45^{\circ}$ with horizontal. The tree height is calculated by adding the distance between tree and observer to the height of the observer to the position of stretched hands [10].

Dimensions of the plant leaves were measured by placing them on a standard linear graph sheet with each divisions of $1 \mathrm{~cm}$ and subdivisions of $1 \mathrm{~mm}$. Fruit and seed sizes were measured using a Vernier caliper. The morphological features of plant leaf and flowers were observed and compared with available literatures.

\section{Dataset Description}

The dataset associated with this Dataset Paper consists of 26 items which are described as follows.

Dataset Item 1 (Table). Plant morphology of 9 Indian Garcinia species. The average plant height was calculated for the bearing plants. Garcinia shows a variation of height from $8 \mathrm{~m}$ to $25 \mathrm{~m}$. The important feature of Garcinia plants is the copious exudates from wounded leaf and barks. The exudates vary from deep yellow to cream-yellow colour. Though red coloured blazes are a common feature in Garcinia, species like G. pedunculata, G. mangostana, and G. kydia do not produce blaze and G. subelliptica is found to have yellowish tender leaves.

\author{
Column 1: Species \\ Column 2: Height (m) \\ Column 3: Trunk Colour \\ Column 4: Trunk Texture \\ Column 5: Branches
}

Dataset Item 2 (Table). Leaf morphology of 9 Indian Garcinia species. Mature leaves were collected from corresponding trees and observed for morphological features such as dimensions, colour, texture, shape, and venations. Garcinia species are evergreen cauline plants, having opposite decussate foliar arrangement. Garcinia species have simple petiolate leaves. The petioles are so small in plants like G. indica, G. subelliptica and $G$. lanceaefolia that they almost appear to be sessile type leaves. Venation of the leaves is pinnate in all the cases, though the appearance of veins differs. In case of G. cowa, midvein raised abaxially; secondary veins are $12-18$ pairs, near margin joining together; tertiary veins are conspicuous on both surfaces. In case of G. kydia, midvein slightly raised abaxially and secondary veins are visible.

\section{Column 1: Species \\ Column 2: Crown \\ Column 3: Petiole \\ Column 4: Venation}

Dataset Item 3 (Table). Leaf features of 9 Indian Garcinia species. Leaf margins of Garcinia leaves are entire except G. kydia, G. xanthochymus, and G. subelliptica. These three species have involutes leaf margins. Leaves show variation in shape and lamina size. Leaf shape varies a great from lanceolate to obovate and elliptic.

\section{Column 1: Species \\ Column 2: Lamina Size $(\mathrm{cm})$ \\ Column 3: Shape \\ Column 4: Apex \\ Column 5: Base \\ Column 6: Colour and Texture}

Dataset Item 4 (Table). Flower morphology of 9 Indian Garcinia species. It is interesting to note that in north eastern region the flowering season is summer (April-June) while in Western Ghats it is spring (December-March). Garcinia shows two types of flowers, tetramerous (4-petaled) and pentamerous (5-petaled).

\section{Column 1: Species \\ Column 2: Flower Nature \\ Column 3: Season \\ Column 4: Location}

Dataset Item 5 (Table). Flower parts of 9 Indian Garcinia species. Garcinia flowers are mostly sessile (without flower stalk) except G. kydia which has pedicels of 4-7 mm length. Garcinia flowers except G. subelliptica are actinomorphic. Flower buds are round in shape and vary from $0.7 \mathrm{~cm}$ to $1 \mathrm{~cm}$ in diameter. All the flowers did not contain nectar. Garcinia also shows variation in flower colour.

Column 1: Species

Column 2: Colour 


\section{Column 3: Sepals \\ Column 4: Petals}

Dataset Item 6 (Table). Flower parts of 9 Indian Garcinia species. The stamens of Garcinia flowers are epipetalous. Anthers are mostly sessile, 2 celled, and longitudinally dehiscent. Garcinia flowers are hypogenous.

Column 1: Species

Column 2: Stamens

Column 3: Stigma

Column 4: Ovary

Dataset Item 7 (Image). Flower of the Indian species Garcinia indica.

Dataset Item 8 (Image). Flower of the Indian species Garcinia gummi-gutta.

Dataset Item 9 (Image). Flower of the Indian species Garcinia cowa.

Dataset Item 10 (Image). Flower of the Indian species Garcinia kydia.

Dataset Item 11 (Image). Flower of the Indian species Garcinia lanceaefolia.

Dataset Item 12 (Image). Flower of the Indian species Garcinia pedunculata.

Dataset Item 13 (Image). Flower of the Indian species Garcinia subelliptica.

Dataset Item 14 (Image). Flower of the Indian species Garcinia xanthochymus.

Dataset Item 15 (Image). Flower of the Indian species Garcinia mangostana.

Dataset Item 16 (Table). Fruit morphology of 9 Indian Garcinia species. Garcinia fruits are fleshy berry with smooth fleshy pericarp with high diversity in shape and size. The size varies from 2 to $10 \mathrm{~cm}$ in diameter. Arils are acidic and juicy, and the acid content varies from species to species. Garcinia fruits possess an appetising acidic flavour. Fruit size was measured using a Vernier Caliper with horizontal length in diameter.

Column 1: Species

Column 2: Harvest

Column 3: Shape

Column 4: Size (cm)

Column 5: Colour

Column 6: Aril Colour
Dataset Item 17 (Table). Seed morphology of 9 Indian Garcinia species. Seed size is the average length of seeds measured using a Vernier calliper. The number of seeds varies from 1 to 8 in different species.

Column 1: Species

Column 2: Number of Seeds

Column 3: Seed Size (cm)

Column 4: Other Fruit Features

Dataset Item 18 (Image). Fruit of the Indian species Garcinia indica.

Dataset Item 19 (Image). Fruit of the Indian species Garcinia gummi-gutta.

Dataset Item 20 (Image). Fruit of the Indian species Garcinia cowa.

Dataset Item 21 (Image). Fruit of the Indian species Garcinia kydia.

Dataset Item 22 (Image). Fruit of the Indian species Garcinia lanceaefolia.

Dataset Item 23 (Image). Fruit of the Indian species Garcinia pedunculata.

Dataset Item 24 (Image). Fruit of the Indian species Garcinia subelliptica.

Dataset Item 25 (Image). Fruit of the Indian species Garcinia xanthochymus.

Dataset Item 26 (Image). Fruit of the Indian species Garcinia mangostana.

\section{Concluding Remarks}

The study indicates that NE Region of India is a good source of diversity for Garcinia as it is the case in Western Ghats. Morphological characterizations of the species of these two different eco systems indicate variation within the species of the same ecosystem and similarities in the species of two different ecosystems. However, the collection surveys indicated that though many species exist, the population density is dangerously low and is reduced to one or two trees in a given location making survival of these species very difficult. This is further aggravated by the fact that seeds fail to produce seedlings due to various physiological and environmental factors making multiplication and maintenance of these species impossible. Though the fruit product of Garcinia is available in local markets, the awareness of Garcinia as a tree is very rare. In this study, summering of the fruit, leaf, and tree structure has been done which may give awareness about the crop to the people. 


\section{Dataset Availability}

The dataset associated with this Dataset Paper is dedicated to the public domain using the CC0 waiver and is available at http://dx.doi.org/10.1155/2014/823705/dataset.

\section{Conflict of Interests}

The authors declare that they have no conflict of interests regarding the publication of this paper.

\section{Acknowledgments}

The authors acknowledge the Director of IISR, Calicut, Kerala, India, for providing facilities and CSIR for financial support to the SRF.

\section{References}

[1] E. Roberts, Vegetable Materia Medica of India and Ceylon, Bishen Singh Mahendra Pal Singh, Dehra Dun, India, 1984.

[2] The Wealth of India, Raw Materials, vol. 4, CSIR, New Delhi, India, 1956.

[3] P. S. Negi, G. K. Jayaprakasha, and B. S. Jena, "Antibacterial activity of the extracts from the fruit rinds of Garcinia cowa and Garcinia pedunculata against food borne pathogens and spoilage bacteria," Food Science and Technology, vol. 41, no. 10, pp. 1857-1861, 2008.

[4] Y. S. Lewis and S. Neelakantan, "(-)-Hydroxycitric acid-the principal acid in the fruits of Garcinia cambogia desr," Phytochemistry, vol. 4, no. 4, pp. 619-625, 1965.

[5] J. M. Lowenstein, "Effect of (-)-hydroxycitrate on fatty acid synthesis by rat liver in vivo," Journal of Biological Chemistry, vol. 246, no. 3, pp. 629-632, 1971.

[6] C. Sullivan, J. G. Hamilton, O. N. Miller, and V. R. Wheatley, "Inhibition of lipogenesis in rat liver by (-)-hydroxycitrate," Archives of Biochemistry and Biophysics, vol. 150, no. 1, pp. 183190, 1972.

[7] C. Sullivan and J. Triscari, "Metabolic regulation as a control for lipid disorders. I. Influence of (-) hydroxycitrate on experimentally induced obesity in the rodent," The American Journal of Clinical Nutrition, vol. 30, no. 5, pp. 767-776, 1977.

[8] M. Cheek, "Garcinia kola," in IUCN Red List of Threatened Species, IUCN Red List of Threatened Species, 2004, http://www.iucnredlist.org/.

[9] J. D. Hooker, Garcinia, vol. 1, Flora of British India, Periodical experts, Delhi, India, 1875.

[10] M. Beals, L. Gross, and S. Harrell, "Estimation of tree height: right triangle trigonometry," 2000, http://www.tiem.utk.edu/ $\sim$ gross/bioed/bealsmodules/triangle.html. 

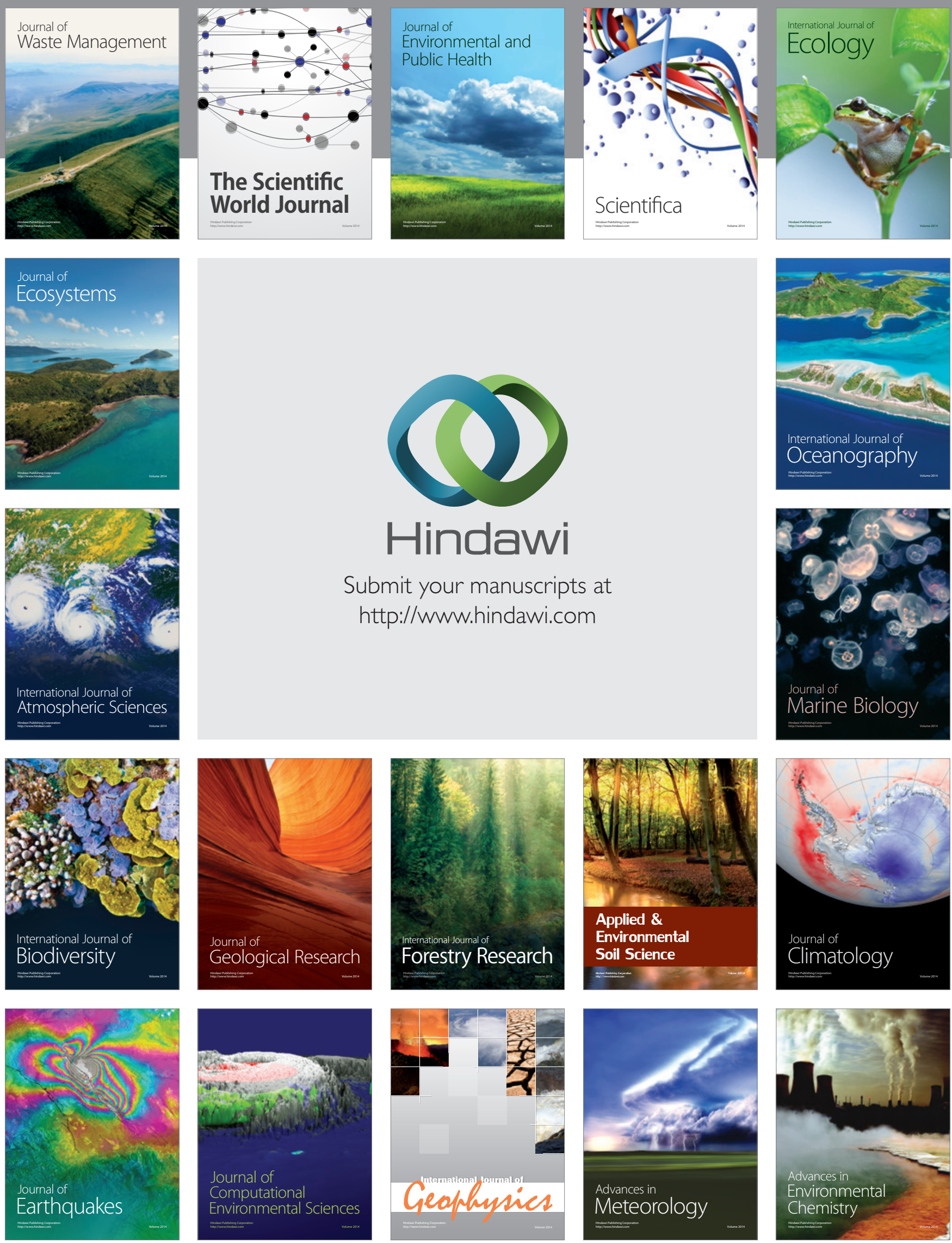